\title{
The Prevalence of Signs of Thyroid Pathology among Students of the Karaganda Medical University According to the Survey
}

\author{
Bekov Yernur Kasipovich ${ }^{1 *}$, Omarbekova Nazgul Kakenovna ${ }^{2}$, Akhmetova Mensulu Kanatovna ${ }^{1}$, \\ Pozdnyakova Yelena Vladimirovna ${ }^{2}$ Moldabayeva Altyn Kabdollovna ${ }^{3}$, Umirbaeva Assel Iltaevna ${ }^{1}$, \\ Alibieva Dinara Toleutayevna ${ }^{1}$, Alyiev Ondassyn Minbaevich ${ }^{4}$, Batyrbekova Lyazat Sarsenbaevna ${ }^{5}$ \\ ${ }^{1}$ Department of Internal Medicine, Faculty of Medicine, Karaganda Medical University, Karaganda, Kazakhstan; ${ }^{2}$ Department of \\ Biomedicine, Faculty of Medicine, Karaganda Medical University, Karaganda, Kazakhstan; ${ }^{3}$ Candidate of Biological Sciences, \\ Head of Department of Laboratory Medicine, Astana Medical University, Astana, Kazakhstan; ${ }^{4}$ Department of Propaedeutic \\ of Internal Medicine, Faculty of Medicine, West Kazakhstan Medical University, Aktobe, Kazakhstan; ${ }^{5}$ Department of Family \\ Medicine, Faculty of Medicine, Karaganda Medical University, Karaganda, Kazakhstan
}

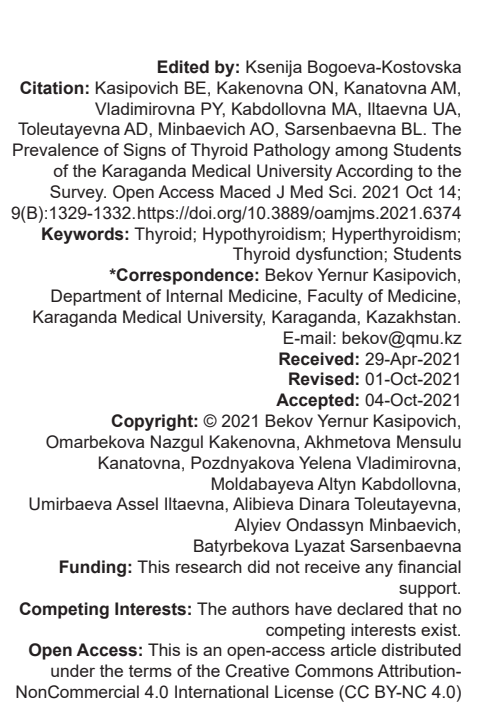

Abstract

AIM: The objectives of the study were to study the signs of thyroid dysfunction in students at the Karaganda Medical University.

MATERIALS AND METHODS: The survey was conducted among students of the Karaganda Medical University in the amount of two hundred people. Statistical methods were used for comparison among students of different courses.

RESULTS: Among junior students, signs of thyroid dysfunction were more pronounced than among senior students. More than half of the examined students had a diagnosed thyroid pathology, which was more pronounced in students of one and two courses.

CONCLUSION: Undergraduates are more likely to exhibit signs of stress-related thyroid dysfunction.

\section{Introduction}

The thyroid gland is an endocrine organ located in the front of the lower part of the neck and extending from the level of the fifth cervical vertebra to the first thoracic region. The gland varies from $\mathrm{H}$ to $\mathrm{U}$-shaped and is formed by two elongated lateral lobes with an upper and lower poles connected by a median isthmus, with an average height of 12-15 $\mathrm{mm}$, lying above the second and fourth tracheal rings, consists of 2 lobes, the mass of which is $25-40 \mathrm{~g}$. When viewed from the front, it has, rather, the shape of a butterfly, however, in all European languages (German Schilddruse, English Thyroid, etc.) it received an incorrect name "thyroid," etymologically derived from the Greek word thyreos. Probably, the gland owes its name to a large extent to its topographic proximity with the thyroid cartilage of the larynx, which in its outlines really resembles the Greek "oblong shield." The thyroid tissue is extremely actively supplied with blood: The level of blood flow in its tissue is about 50 times higher than the level of blood flow in the muscles. In the immediate vicinity of the surface of the thyroid gland, there are extremely important anatomical structures: Large vessels (common carotid artery, internal jugular vein), nerves (recurrent laryngeal nerve and superior laryngeal nerve), trachea, esophagus, and parathyroid glands. It is the proximity of these formations that makes it difficult to perform operations on the thyroid gland - damage to any of them leads to serious, sometimes life-threatening complications.

There are several types of disorders in the function and structure of the thyroid gland:

Goiter: A common name for a swollen thyroid gland. Goiter can be either iodine deficiency or a 
disease associated with inflammation of the thyroid gland called thyroiditis, with various variations.

Thyroiditis: An inflammation of the thyroid gland, usually caused by a viral infection or autoimmune disease. Thyroiditis can be symptomatic or asymptomatic.

Hyperthyroidism: Overproduction of thyroid hormones. Most often hyperthyroidism is caused by Graves' disease

Hypothyroidism: Low production of thyroid hormone. Thyroid damage caused by an autoimmune disease is the most common cause of hypothyroidism.

Thyroid nodule: A small abnormal mass or lump in the thyroid gland. Thyroid nodules are very common. Some of them are cancerous. They may release excess hormones, causing hyperthyroidism, or they may not cause any problems.

A thyroid cyst: A cavity formation in one of the most important glands of the human body -- the thyroid - is a benign, very small tumor that has colloidal contents inside.

\section{Thyroid cancer: An unusual form of cancer.}

Thyroid storm: A rare form of hyperthyroidism in which extremely high levels of thyroid hormones cause severe illness.

In recent years, the problem of treatment and prevention of autoimmune thyroiditis (AIT) has acquired special social significance in connection with the consequences of the progression and outcome of this disease: The onset of insufficient thyroid function. Persistent loss of thyroid function, hypothyroidism, dictates the need for lifelong thyroid hormone replacement therapy. The presence of such a condition in a patient as subclinical hypothyroidism regulates the appointment of low doses of levothyroxine for a long period. At the same time, one of the factors contributing to the development of AIT is long-term intake of iodine-containing preparations or consumption of iodized food products [1], [2], [3], [4] due to the effect of iodine preparations on the immune system [5], [6], [7]. According to a number of researchers [8], [9], [10], unjustified prescription of iodine-containing drugs, as well as justified, but long-term, leads to an increase in the content of antibodies to TPO. Chronic administration of high doses of iodine was accompanied by activation of oxidative stress in the thyroid gland, as evidenced by an increase in the concentration of thiobarbiturate acid and the activity of antioxidant enzymes [10], [11], [12], [13], [14].

At the same time, iodine deficiency states contribute to the emergence of nodes, or benign neoplasms of the thyroid gland, which are very important to distinguish with the oncological process.

AIT with normal thyroid function (euthyroidism) often becomes the subject of medication intervention, especially if it is hypertrophic or has nodules in the thyroid tissue. The latter can be fairly regarded as a combination of AIT with nodular goiter in areas of iodine deficiency endemic (according to the ICD-10 classification, E04.1 Non-toxic single-nodular goiter, E04.2 - Non-toxic multinodular goiter). In such cases, we meet with the practice of prescribing potassium iodide preparations (iodomarin, iodine-balance, potassium iodide, etc.) [9], [15], [16], [17], [18] despite the fact that the National Clinical Protocol does not recommend its application. In this case, the main argument is the reasoning about the endemic lack of iodine in water and food.

In terms of the prevalence of endocrine pathology in the population, AIT takes the $2^{\text {nd }}$ place, second only to diabetes mellitus [5], [19], [20]. According to statistics [19], [21], [22], [23], [24], about 50\% of women aged 30 to 50 years suffer from autoimmune thyroiditis. Among the patients who turned to endocrinologists, almost half suffer from autoimmune thyroiditis - both as an independent disease and in combination with another thyroid pathology [4], [21], [22], [25].

The aim of our work was to conduct a comparative analysis of the presence of symptoms of thyroid pathology among junior and senior students.

\section{Materials and Methods}

To identify signs of thyroid pathology, a questionnaire was used, consisting of 16 questions. The study involved 200 respondents: The number of them revealed signs of thyroid gland pathology 141 people, just with clinical manifestations - 59 people.

The analysis of qualitative features was used. The contingency table for an independent sample.

$$
X^{2}=\frac{(a b-b c)^{2} * n}{(a+b)(c+d)(a+c)(b+d)}
$$

Data analysis was carried out using MS Excel programs and statistical software $\mathrm{R}$

\section{Results and Discussion}

Among the respondents, sleep disorders were found only in 75 out of 141 , of which among $2^{\text {nd }}$ and 3rd-year students with sleep disorders it was $38.67 \%$ each, while the same indicator for 4th-year students was $10.67 \%$ and 5 th-year students $12 \%$ (Figure 1).

Irritability according to the questionnaire out of 141 people was 44 , of which 2 -year students $31 \%$, respectively, $43 \%$ of 3 -year students, $12 \%$ of 4 -year 


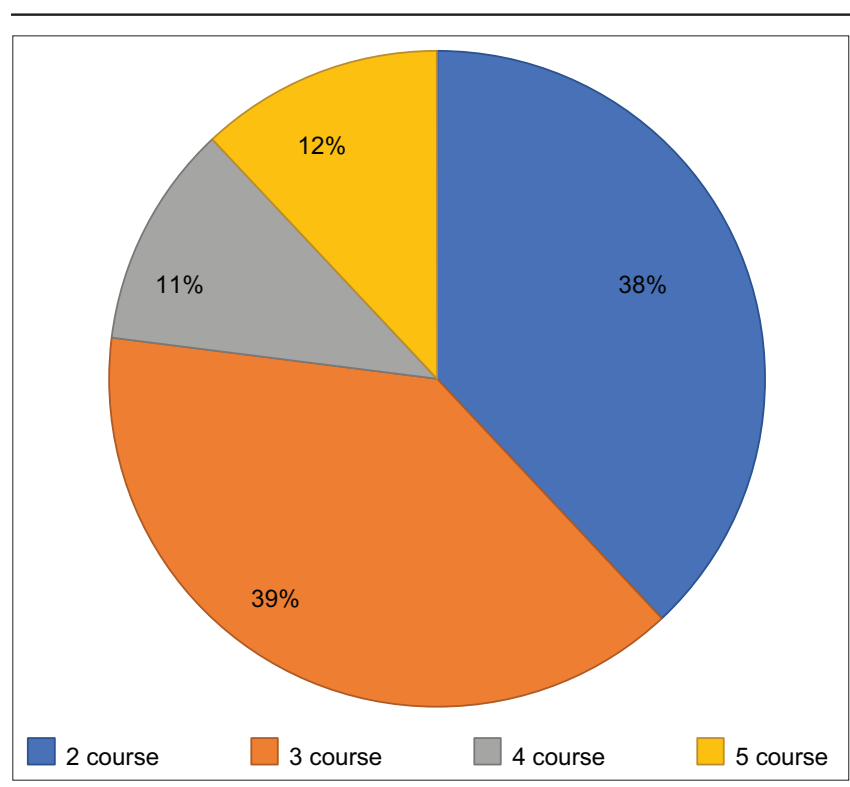

Figure 1: The frequency of occurrence of sleep disorders among students of the courses

students, and $14 \%$ of 5 -year students. The presence of fatigue among the surveyed 141 students 96 people $(68 \%)$, of whom $40 \%$ were found among 2 nd-year students, $44 \%$ and 4 -year students - $6 \%$, as well as 5th-year students $10 \%$ (Figure 2).

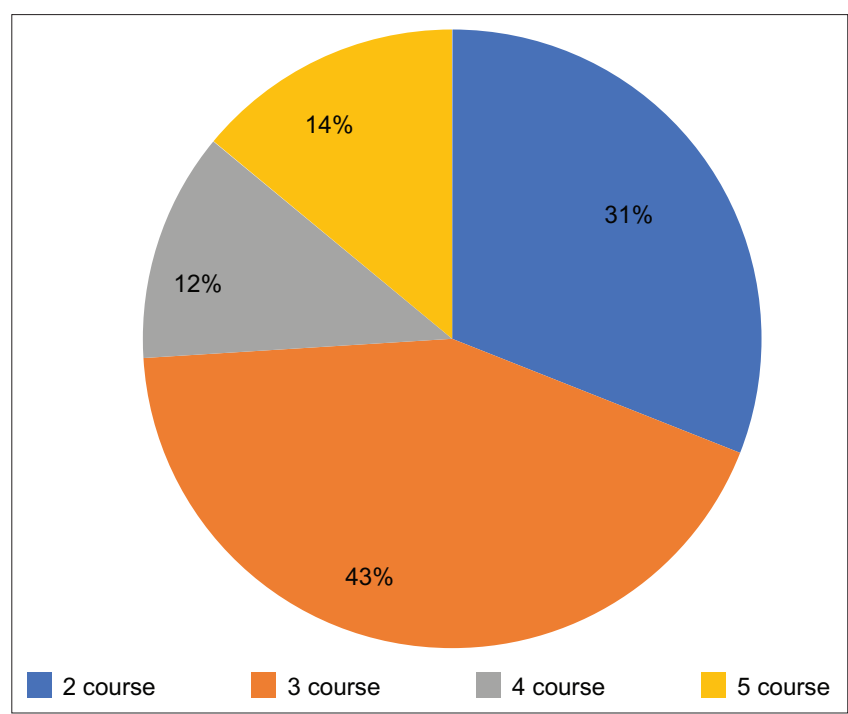

Figure 2: The frequency of occurrence of irritability among students of the courses

As shown in Table 1, among 141 respondents, hair loss was 102 among 141, 36.27\% in 2 courses, $42.16 \%$ in 3 courses, $8.82 \%$ among 4 -year students, and $12.75 \%$ in 5 courses.

Table 1: Other symptoms of chronic fatigue identified during the survey

\begin{tabular}{lll}
\hline No & Questionnaire & $\%$ stated answers \\
\hline 1. & Loss of hair in 102 out of 141 & 72,34 \\
2. & Gaining or loss of the weight with no reasons in 40 out of 141 & 28,37 \\
3. & Stool dysfunction in 31 out Diarrhea (9) & 6,38 \\
& of 141 Constipation (22) & 15,60 \\
4. & Appetite changes in 62 out of 141 & 43,97 \\
\hline
\end{tabular}

The presence of weight gain or weight loss for unexplained reasons among the powder was 40 out of 141 , of which 2 -year students accounted for $45 \%$,
3 -year students - $42.5 \%$, 4-year students - $2.5 \%$, and 5 -year students $-10 \%$, respectively.

Violation of stool in the form of constipation (22 people) or diarrhea (9 people) out of 141 , respectively, in the $2^{\text {nd }}$ course constipation occurred $22.73 \%$, diarrhea $44.44 \%$ (further $C / D$ ), in the $3^{\text {rd }}$ course $-36.36 \% / 33.33 \%$, for the $4^{\text {th }}$ course $-13.64 \% / 0 \%$, for the $5^{\text {th }}$ course $-27.27 \% / 22.22 \%$. Changes in appetite were observed in 62 respondents among 141 respondents: in the $2^{\text {nd }}$ course $-37.10 \%$, the $3^{\text {rd }}$ course $-41.94 \%$, the $4^{\text {th }}$ course $-4.84 \%$, the $5^{\text {th }}$ course $-16.13 \%$.

\section{Conclusion}

In $2^{\text {nd }}$ and $3^{\text {rd }}$ year students, the manifestations of AIT intensified, since clinical disciplines were introduced into the educational process and the GPA was raised from course to course. In senior students, the signs of AIT decreased, taking into account the beginning of cyclic lessons, which made it possible to have more free time for preparation and practice with patients, which allows us to conclude that the adaptation mechanisms of the body were activated against the background of a respite, but by the $5^{\text {th }}$ year, the level of AIT signs slightly increased, which associated with the choice of the future direction.

Proceeding from this, stress-induced signs of AIT are more pronounced in the younger years, since the period of adaptation begins, and they are less pronounced already in the senior years since the adaptation mechanisms are enhanced due to the stabilization of the psycho-emotional state.

\section{References}

1. Ruf $\mathrm{J}$, Carayon P. Structural and functional aspects of thyroid peroxidase. Arch Biochem Biophys. 2006;445(2):269-77. PMid: 16098474

2. Khmelnitsky OK, Eliseeva NA. Hashimoto and de Quervain thyroiditis. Arkh Patol. 2003;65(6):44-8.

PMid:14964969

3. Petunina NA. Clinic, diagnosis and treatment of autoimmune thyroiditis. Probl Endocrinol. 2002;48(6):16-21.

4. Law of the Republic of Kazakhstan "On the Prevention of lodine Deficiency Diseases" Dated October 14, 2003 No. 489-Prevention of Morbidity in the Republic of Kazakhstan, with Amendments and Additions as of January 13, 2014; 2014.

5. Kaufman KD, Rapoport B, Seto P, Chazenbalk GD, Magnusson RP. Generation of recombinant, enzymatically active human thyroid peroxidase and its recognition by antibodies in the sera of patients with Hashimoto's thyroiditis. J Clin Invest. 1989;84(2):394-403. https://doi.org/10.1172/jci114179

PMid:2474568 
6. WHO, UNICEF and ICCIDD Assessment of lodine Defiency Disorders and Monitoring Their Elimination. A Guide Programme Managers. $3^{\text {rd }}$ ed. Geneva: World Health Organization; 2007. p. 98.

7. WHO, multicenter Growth Reference Study Group. Assessment of difference in linear growth among populations in the WHO, multicenter growth reference study. Acta Paediatr. 2006;450:57-66. https://doi.org/10.1111/j.1651-2227.2006.tb02376.x

8. Jonklaas J, Bianco AC, Bauer AJ, Burman KD, Cappola AR, Celi FS, et al. Guidelines for the treatment of hypothyroidism: Prepared by the American thyroid association task force on thyroid hormone replacement. Thyroid. 2014;24(12):1670-751. https://doi.org/10.1089/thy.2014.0028

PMid:25266247

9. Biondi B, Bartalena L, Cooper DS, Hegedüs L, Laurberg P, Kahaly GJ. The 2015 European thyroid association guidelines on diagnosis and treatment of endogenous subclinical hyperthyroidism. Eur Thyroid J. 2015;4(3):149-63. https://doi. org/10.1159/000438750

PMid:26558232

10. Persani L, Brabant G, Dattani M, Bonomi M, FeldtRasmussen U, Fliers E, et al. 2018 European thyroid association (ETA) guidelines on the diagnosis and management of central hypothyroidism. Eur Thyroid J. 2018;7(5):225-37. https://doi. org/10.1159/000491388

PMid:30374425

11. Duntas LH. The role of iodine and selenium in autoimmune thyroiditis. Horm Metab Res. 2015;47(10):721-6. https://doi. org/10.1055/s-0035-1559631

PMid:26361258

12. Wiersinga WM, Duntas $L$, Fadeyev $V$, Nygaard B, Vanderpump MP. ETA guidelines: The Use of L-T4 + L-T3 in the treatment of hypothyroidism. Eur Thyroid J. 2012;1(2):55-71. https://doi. org/10.1159/000339444

PMid:24782999

13. Pearce SH, Brabant G, Duntas LH, Monzani F, Peeters RP, Razvi S, et al. 2013 ETA guideline: Management of subclinical hypothyroidism. Eur Thyroid J. 2013;2(4):215-28. https://doi. org/10.1159/000356507 PMid:24783053

14. Wiersinga WM. Guidance in subclinical hyperthyroidism and subclinical hypothyroidism: Are we making progress? Eur Thyroid J. 2015;4(3):143-8. https://doi.org/10.1159/000438909 PMid:26558231
15. American association of clinical endocrinologists and associazione medici endocrinologi medical guidelines for clinical practice for the diagnosis and management of thyroid nodules. Endocr Pract. 2006;12(1):63-102. https://doi.org/10.4158/ ep161208.gl PMid:16596732

16. Minutes of meetings of the Joint Commission on the Quality of Medical Services of the Ministry of Health of the Republic of Kazakhstan, 2017 Order No. 332 of the Ministry of Health of 27.04.2016; 2016.

17. Hypothyroidism in Adults. Autoimmune Thyroiditis. Clinical Protocol of the Ministry of Health of the Republic of Kazakhstan, Approved by the Ministry of Health of the Republic of Kazakhstan dated August 18, 2017, Protocol No. 26; 2017. https://doi. org/10.20953/2500-1027-2020-3-25-33

18. Ershova GI, Stepanov SA. New approaches to the treatment of autoimmune thyroiditis. Pac Med J. 2005;1:50-2.

19. Guastamacchia E, Giagulli VA, Licchelli B, Triggiani V. The role of iodine and selenium in the development of autoimmune thyroiditis. Endocr Metab Immune Disord Drug Targets. 2015;15(4):288-92. https://doi.org/10.2174/1871530315666150 619094242

20. Fadeev VV. lodine Deficiency and Autoimmune Diseases in the Region of Mild lodine Deficiency: Abstract. Doctor of Medical Sciences, Moscow; 2004. p. 26.

21. Sergeevna BE. Correction of Oxidative Stress in the Complex Treatment of Hypothyroidism: Dissertation. Candidate of Medical Sciences: 14.00.03/Belonozhkina Elena Sergeevna; [Place of defense: Russian Medical Academy of Postgraduate Education], Moscow; 2004. p. 106.

22. Vikulina AS. Lipid Peroxidation Under the Influence of Cytochrome $\mathrm{C}$ and its Complex $\mathrm{C}$ with Anionic Lipids and its Role in Apoptosis Dissertation. Candidate of Biological Sciences: 14.00.03, Moscow; 2004. p. 106

23. Rapoport B, McLachlan SM. Thyroid autoimmunity. J Clin Invest. 2001;108(9):1253-9. PMid:11696565

24. Bresson D, Rebuffat SA, Peraldi-Roux S. Localization of the immunodominant region on human thyroid peroxidase in autoimmune thyroid diseases: An update. J Autoimmune Dis. 2005;2(1):2. https://doi.org/10.1186/1740-2557-2-2 PMid:15769293

25. World Health Assembly. First Special Session Geneva. November 9, 2006 Resolutions and Decision; 2006. 